\title{
Vertical and horizontal photobiont transmission within populations of a lichen symbiosis
}

Post-print/Accepted manuscript

Francesco Dal Grande

Ivo Widmer

Helen H. Wagner

Christoph Scheidegger

DAL GRANDE, F., WIDMER, I., WAGNER, H.H. and SCHEIDEGGER, C. (2012), Vertical and horizontal photobiont transmission within populations of a lichen symbiosis. Molecular Ecology, 21: 3159-3172. doi:10.1111/j.1365-294X.2012.05482.x

This is the peer reviewed version of the following article: DAL GRANDE, F., WIDMER, I., WAGNER, H.H. and SCHEIDEGGER, C. (2012), Vertical and horizontal photobiont transmission within populations of a lichen symbiosis. Molecular Ecology, 21: 3159-3172, which has been published in final form at doi:10.1111/j.1365-294X.2012.05482.x This article may be used for non-commercial purposes in accordance with Wiley Terms and Conditions for Self-Archiving.

\section{HOW TO CITE TSPACE ITEMS}

Always cite the published version, so the author(s) will receive recognition through services that track citation counts, e.g. Scopus. If you need to cite the page number of the TSpace version (original manuscript or accepted manuscript) because you cannot access the published version, then cite the TSpace version in addition to the published version using the permanent URI (handle) found on the record page. 
1 Vertical and horizontal photobiont transmission within populations of a lichen symbiosis

3 F. Dal Grande ${ }^{1,3} *$, I. Widmer ${ }^{1,4}$, H.H. Wagner ${ }^{2}$, C. Scheidegger ${ }^{1}$

$5{ }^{1}$ Biodiversity and Conservation Biology, WSL Swiss Federal Research Institute, 8903 Birmensdorf,

$6 \quad$ Switzerland

$7 \quad{ }^{2}$ Department of Ecology and Evolutionary Biology, University of Toronto, L5L 1C6 Mississauga, 8 Canada

$9{ }^{3}$ Present Address: Biodiversity and Climate Research Centre (BiK-F), Senckenberg Gesellschaft

10 fuer Naturforschung, 60325 Frankfurt am Main, Germany

$11{ }^{4}$ Present Address: LPED - Laboratory of Population Environment Development, University of

12 Provence, 13331 Marseille Cedex 03, France

13 *These two authors contributed equally to this work and are considered joint first authors.

15 Corresponding Author: Dal Grande Francesco

16 Biodiversity and Climate Research Centre (BiK-F), Senckenberg Gesellschaft fuer

17 Naturforschung, 60325 Frankfurt am Main, Germany - Tel. +49 (0)69 79824798 Fax. +49

$18 \quad(0) 6979824771$

19 e-mail: Francesco.DalGrande@senckenberg.de, francesco.dalgrande@wsl.ch

20 Keywords: Population Genetics - Empirical, Ecological Genetics, Algae, Fungi, Lobaria

21 pulmonaria, Microsatellite

22 Running head: Dynamics of a lichen symbiosis 


\section{Abstract}

24 Lichens are widespread symbioses and play important roles in many terrestrial ecosystems. The 25 genetic structure of lichens is the result of the association between fungal and algal populations 26 constituting the lichen thallus. Using eight fungus- and seven alga-specific highly variable

27 microsatellite markers on within-population spatial genetic data from 62 replicate populations across

28 Europe, North America, Asia and Africa, we investigated the contributions of vertical and horizontal

29 transmission of the photobiont to the genetic structure of the epiphytic lichen Lobaria pulmonaria.

30 Based on pairwise comparisons of multi-locus genotypes defined separately for the mycobiont and

31 for the photobiont, we inferred the transmission mode of the photobiont and the relative contribution

32 of somatic mutation and recombination. After constraining the analysis of one symbiont to pairs of

33 individuals with genetically identical symbiotic partners, we found that $77 \%$ of fungal and $70 \%$ of

34 algal pairs were represented by clones. Thus, the predominant dispersal mode was by means of

35 symbiotic vegetative propagules (vertical transmission), which dispersed fungal and algal clones co-

36 dependently over a short distance, thus shaping the spatial genetic structure up to distances of $20 \mathrm{~m}$.

37 Evidence for somatic mutation generating genetic diversity was found in both symbionts, accounting

38 for $30 \%$ of pairwise comparisons in the alga and $15 \%$ in the fungus. While the alga did not show

39 statistically significant evidence of recombination, recombination accounted for $7.7 \%$ of fungal

40 pairs with identical algae. This implies that, even in a mostly vegetatively reproducing species,

41 horizontal transmission plays a role in shaping the symbiotic association, as shown in many coral

42 and other symbioses in nature.

\section{Introduction}


45 Lichens are symbiotic organisms composed of a fungal partner (mycobiont) and a population of 46 algae and/or cyanobacteria (photobiont). Mycobionts express their symbiotic phenotype only in 47 association with compatible photosynthetic partners, and the tight morphological integration and 48 physiological dependence of the symbionts result in a distinct lichen body called thallus (Ahmadjian 49 1993). In lichens, the mechanism for symbiotic contact and thallus formation in nature is only 50 partially understood. Reproduction and dispersal of lichens is a complex process since both partners 51 have to be present for the successful development of a new lichen thallus (Honegger 1998, 2008;

52 Dobson 2003). A vast majority of lichens have a sexual and asexual life cycle. In the sexual life 53 cycle, fungal spores are released from specialized structures on the thallus (ascomata). Upon 54 germination, fungal spores must obtain a compatible algal or cyanobacterial partner, which may be 55 free-living (Etges \& Ott 2001; Sanders \& Lücking 2002; Sanders 2005; Handa et al. 2007; Hedenås 56 et al. 2007; Macedo et al. 2009) or obtained through capture from another lichen (Friedl 1987; Ott

57 1987a,b; Stenroos 1990; Rambold \& Triebel 1992; Ott et al. 1995; Gaßmann \& Ott 2000; Lücking

$58 \&$ Grube 2002). In the vegetative life cycle, mycobiont and photobiont are simultaneously dispersed

59 within specialized asexual propagules (e.g., corticated protuberances called isidia or non-corticated

60 clumps called soredia) or through thallus fragmentation.

61 The genetic structure of a lichen population will be strongly influenced by the manner in

62 which photobionts are dispersed and transmitted to the fungus (Hill 2009). Vertical (or co-

63 dependent) transmission occurs when the photobiont disperses as part of the vegetative propagule of

64 the lichen, thus presumably representing the predominant process in exclusively or nearly

65 exclusively asexual lichen species (Werth \& Sork 2010). The vegetative propagules produce

66 physically separate but genetically identical thalli, i.e., thalli with fungal and algal components 
67 genetically identical to the mother thallus (Paulsrud et al. 1998; Doering \& Piercey-Normore 2009).

68 On the other hand, horizontal (or independent) transmission usually occurs when the fungus

69 reproduces sexually. The sexual life cycle is considered to reshuffle the genetic composition of the

70 lichen, generating new combinations of fungal and algal genotypes (i.e., genetically different thalli).

71 Horizontal transmission may also depend on the dispersal ability of the photobiont. The ability of

72 green-algal photobionts to move is very restricted, as they usually do not disperse (either sexually or

73 asexually) while embedded in the lichen thallus (Sluiman et al. 1989; Nash 1996). However, many

74 green-algal photobionts can occur in free-living populations on soil, rocks, or tree stems (Mukhtar et

75 al. 1994; Beck et al. 1998; Friedl \& Büdel 2008), and viable photobiont cells are found in fecal

76 pellets of lichenivorous snails (Meier et al. 2002; Boch et al. 2011). Moreover, horizontal

77 transmission of algae has been shown in asexual (e.g., Nelsen \& Gargas 2008, 2009) or nearly

78 asexual (Piercey-Normore 2006; Wornik \& Grube 2010) lichen species.

Studies on the mode of transmission of lichen photobionts in natural populations remain

80 scarce. In particular, the genetic composition of a lichen thallus (i.e., its individual mycobiont and

81 photobiont genotypes) and its fine-scale spatial distribution has never been reliably assessed at the

82 within population scale due to the lack of appropriate genetic markers. Marker resolution becomes in

83 fact critical when studying highly clonal organisms such as lichens, for which multilocus genotypes

84 are the only way to identify genetically distinct individuals (Arnaud-Haond et al. 2007).

85 This work aims to assess the relative contribution of vertical vs. horizontal transmission to

86 the intra-population genetic structure of the mycobiont and of the photobiont of a mainly vegetative

87 lichen species. The model species is the epiphytic lichen L. pulmonaria, which is widespread in the

88 Northern Hemisphere (Yoshimura 1971). Recently, microsatellite markers have been developed for 
89 its haploid eukaryotic symbionts (mycobiont: Walser et al. 2003; Widmer et al. 2010; this study;

90 green algal photobiont: Dal Grande et al. 2010). The high mutation rate of microsatellite loci gives

91 them a far greater resolving power than previous, sequence-based studies performed on lichen

92 populations (e.g., Beck et al. 2002; Lohtander et al. 2003; Printzen et al. 2003; Printzen \& Ekman

93 2003; Yahr et al. 2004; Lindblom \& Ekman 2005, 2007; Selkoe \& Toonen 2006; Doering \&

94 Piercey-Normore 2009; Lättmann et al. 2009; Werth \& Sork 2010). Lobaria pulmonaria is highly

95 selective towards its green algal photobiont, i.e., it is associated with the coccoid green alga

96 Dictyochloropsis reticulata (Tschermak-Woess) Tschermak-Woess throughout its entire

97 distribution range (Dal Grande 2011).

98 Earlier studies suggested that the predominant dispersal mode in L. pulmonaria is by means

99 of vegetative propagules (Zoller et al. 1999; Walser 2004; Wagner et al. 2005, 2006; Werth et al.

100 2006a,b, 2007), and showed its mycobiont populations to be highly clonal, suggesting a

101 predominance of vertical transmission of the photobiont. However, the mycobiont of L. pulmonaria

102 can undertake sexual reproduction, hence the photobiont also needs to be transmitted horizontally.

103 While no evidence of free-living photobiont populations has been found to date (Tschermak-Woess

104 1978; Dal Grande 2011), the presence of zoospores (motile flagellate asexual cells) indicates that the

105 photobiont has the potential to move locally (i.e., on the same tree) once released from the thallus

106 (Richardson 1999; Friedl \& Büdel 2008).

107 The availability of symbionts may impose limits on the distribution of the other partner,

108 particularly in cases where the association is obligate (Andras et al. 2011). Werth et al. (2007)

109 demonstrated for the mycobiont of L. pulmonaria that gene flow is spatially restricted, resulting in

110 spatial aggregation of fungal clones. Based on the notion that spatial processes, such as reproduction 
111 followed by dispersal, leave a characteristic spatial signature (Seabloom et al. 2005; Wagner \&

112 Fortin 2005), analysis of spatial genetic structure may be used to identify the underlying processes.

113 In particular, vertical transmission of the photobiont is expected to result in short-distance spatial

114 aggregation of fungal and algal clones, while horizontal transmission due to mycobiont sexual

115 reproduction will decouple photobiont-mycobiont pairs at larger distances (Werth \& Sork 2010).

116 This paper addresses the following questions: (a) what is the relative contribution of vertical

117 vs. horizontal transmission of the photobiont to the genetic structure of the lichen populations? (b)

118 What is the relative contribution of the micro-evolutionary processes of mutation and recombination

119 to the current fungal and algal intra-population genetic diversity? (c) Are there differences in the

120 within-population spatial genetic structure between mycobiont and photobiont?

121 To address these questions, we introduce an approach that takes advantage of the

122 microsatellite markers for both the fungal and algal partners. This method allows for the reliable

123 identification of clonal thalli (i.e., thalli with identical multilocus genotypes for the fungus and the

124 alga, respectively). Under the assumption that pairs of thalli with identical multilocus genotypes

125 both for the fungus $\left(\mathrm{MLG}_{\mathrm{F}}\right)$ and for the alga $\left(\mathrm{MLG}_{\mathrm{A}}\right)$ within a population result from the vegetative

126 co-dispersal of fungal and algal clones, we can infer within-population evolutionary processes (such

127 as mutation and recombination) by restricting analysis for one symbiont to pairs of thalli with

128 identical MLG in the other symbiont. While statistical inference of (spatial) genetic structure within

129 populations is often limited by a lack of independent replicate populations, we illustrate our

130 approach with a data set of 62 range-wide populations that allows robust statistical analysis.

131 This research assesses the way photobionts are transmitted in a predominantly asexual taxon

132 and provides insights into the contribution of the micro-evolutionary processes of mutation and 
133 recombination to the genetic structure of lichen populations.

\section{Materials and Methods}

136 Sample collection and molecular genetic analysis

137 The goal of our design was to detect the intra-population genetic structure of the fungal and algal 138 symbionts of L. pulmonaria among adjacent trees. This design would not detect either the extent of

139 the overall genetic clustering on the same tree or the extent of gene flow among populations. In total, 1402229 thalli of L. pulmonaria were sampled from 62 populations across Europe, North America, Asia 141 and Africa (Table S1, Supporting Information). The median distance between a population and the 142 nearest neighbor sampled population was $115 \mathrm{~km}$, and all but nine populations were at least $25 \mathrm{~km}$

143 from their nearest neighbor population. For the purpose of our analyses, a population was defined as 144 a stand of trees colonized by L. pulmonaria. Across each population, $1-3$ thalli were randomly 145 taken from an average of 23 nearest neighbor trees (i.e., proceeding from a sampled tree to its 146 nearest unsampled neighbor tree). The maximum distance among the sampled trees within each 147 population typically was $<1500 \mathrm{~m}$ except for three populations, with a median maximum distance 148 of $274 \mathrm{~m}$ and a minimum of $16 \mathrm{~m}$. Thalli collected on a single tree were separated by about $50 \mathrm{~cm}$

149 and positioned on different sides of the trunk. This sampling design allows for the investigation of

150 microsatellite variation within a population of L. pulmonaria (Walser et al. 2003; Wagner et al.

151 2005). On average 31 thalli were collected per population, which has been found to be an 152 appropriate number to resolve within-population mycobiont and photobiont genetic structure (Werth 153 2010).

154 Eight fungus-specific (LPu03, LPu09, LPu15, LPu23, LPu24, LPu25, LPu28, Walser et al. 
155 2003; Widmer et al. 2010; MS4, this study) and seven alga-specific microsatellite markers (LPh1 to

156 LPh7; Dal Grande et al. 2010) were amplified from total lichen DNA. For primer sequences,

157 including redesigned primers for LPu25, labeling and PCR conditions see Table S2 (Supporting

158 Information). Fragment lengths were determined on a 3730 DNA Analyzer (Applied Biosystems,

159 Foster City, CA), and electropherograms were analyzed with GENEMAPPER 3.7 (Applied

160 Biosystems, Foster City, CA) using LIZ-500 as internal size standard. Multilocus genotypes were

161 defined separately for the fungus $\left(\mathrm{MLG}_{\mathrm{F}}\right.$, based on eight loci) and for the alga $\left(\mathrm{MLG}_{\mathrm{A}}\right.$, based on

162 seven loci).

164 Statistical analyses

165 Data sets

166 Recurrent MLGs could either be the result of vegetative reproduction or chance products of 167 sexual reproduction (Arnaud-Haond et al. 2007). Therefore, recurrent MLGs were only interpreted

168 as clones if they were unlikely to result from sexual reproduction given the observe allele

169 frequencies in a population. We calculated for each population the probability of observing two

170 sexually produced fungal or algal individuals identical at all eight or seven microsatellite loci,

171 respectively. This method, implemented in the software GENCLONE v2.0 (Arnaud-Haond \&

172 Belkhir 2006), is based on the round-robin method proposed by Parks \& Werth (1993), which allows

173 for each MLG an estimate of the probability of obtaining the observed number of recurrent MLGs in

174 the data set by sexual reproduction under random mating $\left(\mathrm{P}_{\mathrm{sex}}\right)$. The method thus takes into account

175 relative levels of polymorphism (Supplementary Material, Table S4). We used the $\mathrm{P}_{\text {sex }}$ to assess the

176 likelihood that identical MLGs were of sexual origin. The significance of $\mathrm{P}_{\text {sex }}$ was tested at $\alpha=0.05$ 
177 with 1000 simulations. When significant (i.e., $\left.\mathrm{P}_{\mathrm{sex}}<0.05\right)$, we considered recurrent MLGs as true

178 clones. Recurrent MLGs with $\mathrm{P}_{\text {sex }} \geq 0.05$ were excluded from analyses (Arnaud-Haond et al. 2007).

179 To analyze the genetic diversity of the fungal and algal symbionts, each pair of thalli of $L$.

180 pulmonaria was analyzed for the number of microsatellite loci at which they differed in the fungal

181 genotype $\mathrm{MLG}_{\mathrm{F}}$ (“deltaF”) and in the algal genotype $\mathrm{MLG}_{\mathrm{A}}$ (“deltaA") (see Fig. 1 for a graphic

182 representation). All analyses were restricted to pairwise comparisons of thalli within populations.

183 Three subsets A, B and C of the data were used for analysis as defined in Table 1.

184 Pairwise comparisons within populations are not independent, hence statistical tests cannot

185 rely on parametric tests and true replication requires independent data from multiple study sites. To

186 allow for robust statistical estimation, we pooled data over all 62 populations and derived bootstrap

187 estimates of standard errors in R (R Development Core Team 2008) by leaving out one population at 188 a time.

\section{Relative contribution of vertical vs. horizontal photobiont transmission}

191 Pairs of thalli were scored as resulting from co-dependent dispersal of the symbionts (vertical

192 photobiont transmission) if they had identical MLGs of both the fungus and the alga, i.e.,

193 delta $\mathrm{A}=$ deltaF $=0$. We assessed the relative contribution of vertical photobiont transmission to

194 population genetic structure by the proportion of pairs of thalli with identical MLGs for both

195 symbionts among the pairs of thalli in data set B. We derived a bootstrap estimate of this proportion 196 by omitting one population at a time.

197 Since the sexual life cycle is considered to be the main factor responsible for the independent

198 dispersal of the symbionts (horizontal photobiont transmission), creating new genotypic 
combinations of fungi and algae, we further analyzed pairs of thalli with different MLGs for the

200 fungus and/or the alga. We modeled the contribution of somatic mutation and recombination to the

201 observed differences at the microsatellite loci as follows (see Fig. 2):

202

(i) Empirical null-model of recombination (Fig. 2, top). Recombination may result in pairs of

203 thalli with any number of differing loci. We derived an empirical null model of the distribution of

204 the expected number of loci difference (deltaA or deltaF) based on observed allele frequencies

205 within each population. We permuted repeat lengths for each microsatellite marker among the thalli

206 sampled from the same population (data set A), separately for the alga and for the fungus. We thus

207 simulated thalli with new MLGs based on the observed allele frequencies within each population

208 under the assumption of random mating within populations, taking into account observed levels of

209 marker polymorphism and clonality in each population. We repeated the simulation 100 times and

210 evaluated for each run the frequency distribution of number of loci differing between each pair of

211 simulated thalli from the same population (deltaA, deltaF). We pooled the simulated frequencies

212 across the 62 populations for each simulation run and then averaged over all 100 simulation runs.

213 All calculations were performed in R (R Development Core Team 2008). Simulated probabilities for

214 obtaining identical MLGs by recombination were $3.4 * 10^{-4}$ for deltaF=0 and $6.4 * 10^{-4}$ for

$215 \operatorname{delta} A=0$ (not shown in Fig. 2).

216 (ii) Negative exponential distribution model accounting for somatic mutation (Fig. 2, center).

217 Mutations are assumed to occur independently for each locus and for each symbiont. Hence, over

218 many generations and in an otherwise only vegetatively reproducing population, mutation will first

219 lead to difference in a single locus, a subsequent mutation to difference in one additional locus, and

220 so on, following a negative exponential model defined by parameter lambda. 
(iii) Model fitting to the fungal and algal data (Fig. 2, bottom). To assess to what degree the

222 observed non-clonal pattern in a symbiont was the result of mutation versus recombination, the

223 parameter lambda of an exponential function was fitted to data set $\mathrm{C}$ using the function 'nls' in R (R

224 Development Core Team 2008) and accounting for the null model of recombination. This resulted in

225 estimates for lambda of 0.55 for the fungus and 0.77 for the alga. We then performed a linear

226 regression of the frequency distribution of the number of differing loci as a function of the

227 exponential model (representing mutation) with the fitted parameter lambda and the null model of

228 recombination, with no intercept, and assessed model fit, statistical significance of regression

229 coefficients, and the relative contribution of the exponential model and the empirical null model of

230 recombination to the frequency of pairs per number of differing loci. For each level of deltaA or

231 deltaF, we assessed the proportional contribution by each component model to the fitted value (e.g.,

232 if 100 pairs were predicted, 37 may be predicted by the exponential model and 63 by the empirical

233 null model of recombination). We multiplied these proportions by the observed frequency of each

234 level of deltaA or deltaF in data set $\mathrm{C}$ to estimate the ratio of mutation vs. recombination among the

235 non-clonal component. Bootstrap mean and standard error of this ratio were determined by leaving

236 out one population at a time.

237 Assuming an average microsatellite mutation rate of $10^{-3}$, the expected probability of

238 observing at least one mutation in the alga (with 7 independent loci) is 0.0068 , the expected

239 probability of observing at least one mutation in the fungus (with 8 independent loci) is 0.0077 . The

240 expected probability of mutation occurring in both symbionts independently at the same time is $(6.8$

$\left.241 * 10^{-3}\right) *\left(7.7 * 10^{-3}\right)=5.2 * 10^{-5}$. The probability that both symbionts show a somatic mutation was

242 thus expected to be less than $1 \%$ of the probability for somatic mutation in either symbiont and 
243 considered negligible.

\section{Spatial genetic structure}

246 To assess spatial genetic structure within populations, we determined for data set A the probability

247 of sampling a pair of thalli from the same population belonging to one of the following categories as

248 a function of their distance in space: (i) clonal thalli (deltaF=delta $A=0$ ), (ii) fungal clones associated

249 with different algal MLGs (deltaF=0 and delta $A>0$ ), (iii) algal clones associated with different

250 fungal MLGs (deltaF $>0$ and deltaA=0) and (iv) different fungal MLGs associated with different

251 algal MLGs (deltaF $>0$ and deltaA $>0$ ). The first distance class contained pairs of thalli sampled from

252 the same tree. Distance class boundaries were defined on a logarithmic scale, with the last distance

253 class containing all pairwise comparisons at distances $>500 \mathrm{~m}$.

\section{Results}

256 After exclusion of recurrent MLGs that were not assessed as true clones $\left(\mathrm{P}_{\text {sex }}\right.$ values $>0.05,209$

257 thalli), had incomplete genotype assessment (55 thalli) or missing spatial coordinates ( 5 thalli), the

258 data set consisted of 1960 thalli. We found 1051 MLGs for the haploid fungus and 1025 MLGs for

259 the haploid alga, with a total of 1256 MLGs based on all 15 markers from both symbionts (Table S1,

260 Supporting Information: numbers of different MLGs per population; Table S4, Supporting

261 Information: allele frequency distribution per population at eight fungal and seven algal loci).

262 Multiple fungal or algal genotypes within the same thallus were not found in any of the populations.

263 Our analyses were based on 36,218 pairwise comparisons within populations pooled over 62

264 populations (Table 1). The relative frequency distribution of the number of loci differences (deltaA, 
265 deltaF; calculated over all pairs within populations (data set A) was similar for both symbionts, with

266 the highest frequency of thalli differing by four loci each for the fungus and for the alga (Fig. 3A). In

267 both symbionts, we found a high frequency of identical pairs of thalli (2977 pairs with deltaA=0;

2683285 pairs with deltaF=0; Fig. 3A).

269

270 Vertical transmission of the photobiont

2712294 pairs had identical MLGs both for the alga and the fungus (deltaA=deltaF=0). When the

272 analysis was restricted per symbiont to those pairs of thalli displaying an identical MLG in the other

273 symbiont (data set B), both the alga and the fungus displayed a high degree of clonality, with

$274 \operatorname{delta} \mathrm{A}=0$ and $\operatorname{deltaF}=0$ as the predominant classes (Fig. 3B). The proportion of clonal comparisons

275 was higher for the fungus $(77.06 \% \pm 0.72 \%)$ than for the alga $(69.85 \% \pm 0.60 \%)$.

Identifying micro-evolutionary processes of mutation and recombination

278 After the exclusion of recurrent genotypes within each population and constraining by clonality in

279 the other symbiont (deltaF=0 for algal MLGs and vice versa, data set $\mathrm{C}$ ), we found 215 algal and

280269 fungal pairs of MLGs that differed from each other in at least one locus (Table 1, Fig. 3C). For

281 both symbionts, the largest proportion of these pairs differed at only one locus (deltaA or deltaF=1).

282 The alga showed a strongly skewed distribution of the number of loci differences as expected under

283 a negative exponential model resulting from mutation (Fig. 3C, left). In the fungus, the distribution

284 was bimodal, suggesting the presence of an additional process (Fig. 3C, right).

285 In fungal sexual reproduction, each ascoma (i.e., reproductive structure of the fungus) may

286 either form meiotic fungal spores with the same MLGs or spores with different MLGs. Both spore 
287 types may form new associations with either the same or a different algal MLG. The empirical null 288 models of recombination based on the observed allele frequencies estimated that under random 289 mating within each population, 0.033 percent of fungal recombinations and 0.065 percent of algal

290 recombinations would result in the same MLG as the mother thallus. The secondary peak in the

291 distribution of deltaF given deltaA $=0$ was proportional to the frequency distribution expected from

292 the empirical null-model of recombination (Fig. 3C, right). The combination of an exponential

293 model representing mutation and the empirical null model of recombination explained the

294 distribution of the number of loci differences for each pair of fungi with identical algae well,

295 explaining a total of $96.5 \%$ of the variation for the fungus, whereas for the alga, the exponential

296 model alone explained $98.5 \%$ of the variation (Table S3, Supporting Information). Taking into

297 account the above estimate of $77.06 \%( \pm 0.72 \%)$ clonality in the fungus, the fitted models resulted

298 in an overall estimate of $15.21 \%( \pm 0.25 \%)$ of pairwise comparisons of fungal MLG being affected

299 by mutation and $7.73 \%( \pm 0.25 \%)$ being affected by recombination. For the alga with $69.85 \%$

300 clonality $( \pm 0.60 \%)$, mutation thus accounted for $30.15 \%$.

301

302 Spatial genetic structure

303 Clonality depended strongly on distance (Fig. 4). There was a marked decrease in the frequency of 304 pairs of thalli with identical fungal and algal MLGs (vertically transmitted photobionts,

305 deltaF $=$ deltaA $=0$ ) within the first $20 \mathrm{~m}$, compensated by an increase in the frequency of pairs that 306 differed both in the alga and in the fungus (deltaF $>0$ and deltaA $>0$ ).

307 The relative frequency of distance classes for each type of pairs showed significant

308 differences between the two symbionts (Fig. 5). For the alga, pairs with differences at 1 or more loci 
309 (deltaA $>0$, deltaF $=0$ ) decreased in number over short distances, similarly to the distribution of clonal

310 thalli. Fungal MLG pairs differing at least at one locus (deltaF $>0$, deltaA $=0$ ) showed a different

311 spatial pattern similar to that of pairs differing in both symbionts (deltaF>0, deltaA $>0$ ).

\section{Discussion}

314 Prevalence of vertical transmission of the photobiont

315 Based on previous evidence that the fungus reproduces mainly clonally (Walser 2004; Wagner et al.

316 2005; Werth et al. 2006b, 2007), we expected the photobiont of L. pulmonaria to disperse primarily

317 vertically within vegetative propagules. Vegetative reproduction will recreate the MLG of the

318 mother thallus unless there is mutation in at least one symbiont. This should result in a dominating

319 component of pairs of thalli displaying identical MLGs for both symbionts. Indeed, when the

320 analysis was restricted per symbiont to those pairs of thalli displaying an identical MLG in the other

321 symbiont (data set B), we found that the predominant class of MLG comparisons was composed of

322 pairs of thalli having identical MLGs for both symbionts. The probability of creating identical

323 MLGs through sexual reproduction was small enough to be neglected (as tested here with $\mathrm{P}_{\text {sex }}$ for

324 each MLG, and further supported by the empirical null model of recombination, which estimated the

325 overall probability, combined for all MLGs within a population, at less than $0.1 \%$ for either

326 symbiont), therefore we interpreted recurring MLGs as clones, i.e., resulting from vegetative

327 reproduction. Thus, based on microsatellite fingerprinting of both lichen symbionts, we

328 demonstrated that the photobiont of L. pulmonaria is mostly vertically transmitted.

329 Vegetative dispersal with symbiotic propagules ensures the continuity of a successful

330 combination of MLGs of the two partners across generations (Margulis 1993; Yahr et al. 2004, 
331 2006; Reeve \& Hölldobler 2007; Zilber-Rosenberg \& Rosenberg 2008). It has been suggested that

332 vegetative dispersal in lichens has the advantage of producing large numbers of locally adapted

333 propagules that can readily exploit and colonize the local environment (Ott 1987b; Sanders \&

334 Lücking 2002; Walser 2004). A predominance of vertical transmission of photobionts has also been

335 confirmed in other multicellular symbiotic systems for which genetic uniformity is favored by

336 selection for cooperative traits (Gilbert et al. 2009). For instance, in some symbiotic systems, such

337 as maternally inherited endosymbionts (Saffo 1992; Moran \& Baumann 1994; Huigens et al. 2000),

338 grass endophytes (Clay 1990; Saikkonen et al. 2002), corals (Coates \& Jackson 1987) or sea

339 anemones (Geller \& Walton 2001), strong population structure and shared phylogenetic history of

340 symbionts are expected because of the vertical transmission of symbionts (Brem \& Leuchtmann

$3412003)$.

342

343 Contribution of mutation and recombination to within-population genetic structure of lichen

344 symbionts

345 The high variability of the microsatellite markers used in this study, combined with the approach

346 constraining the analyses of one symbiont to pairs of individuals with genetically identical symbiotic

347 partners and the availability of data from 62 replicate populations, provided robust evidence for

348 patterns of mutation and recombination in L. pulmonaria symbionts. The alga showed a clear signal

349 of mutation as indicated by the exponential distribution of the number of loci differences (Fig. 3C,

350 left). Considering that no statistically significant signal of recombination was found, our results

351 indicate that the photobiont $D$. reticulata may reproduce strictly asexually. In lichen photobionts, the

352 production of zoospores (motile, flagellate spores) is considered a means to escape from the thallus, 
353 close to which they can form colonies (Slocum et al. 1980; Scheidegger 1985). The occurrence of

354 free-living colonies is known for the green-algal genus Trebouxia (Tschermak- Woess 1978;

355 Bubrick et al. 1985; Mukhtar et al. 1994), and their zoospores are known to frequently undergo

356 sexual fusion in fresh cultures (Ahmadjian 1959). Despite extensive investigation, the production of

357 zoospores was never observed in the photobiont of L. pulmonaria (Skaloud 2008).

358 It is remarkable that the alga, with one marker less than the fungus, exhibited a comparable

359 level of genetic diversity within populations to the fungus (Fig. 3A). With no evidence for

360 recombination and having shown that the alga is mostly co-transmitted vertically with the

361 mycobiont, this may be the result of faster mutation rates in the algal microsatellites combined with

362 a greater number of generations in the photobiont. An alternative explanation involves the

363 introduction of new alleles into the populations through the horizontal transmission (symbiont

364 capture) from other photobiont populations found in lichen species associated with $D$. reticulata

365 (genera Lobaria and Sticta; Dal Grande 2011). The evidence of mutation obtained in our study

366 concurs with the hypothesis that mutation is the key process creating genetic diversity in clonal

367 organisms (Higgs \& Woodcock 1995; Tomiuk et al. 1998; Butlin 2002; Vogler et al. 2006; Ally et

368 al. 2008; Mock et al. 2008).

369 The sporadic presence of fruiting bodies in L. pulmonaria indicates that the mycobiont can

370 undertake sexual reproduction by forming ascospores. Sexual reproduction involves the process of

371 relichenization, i.e., the formation of a new thallus once fungal spores found a suitable alga

372 (horizontal transmission). Our results show that recombination significantly contributes to the fungal

373 genetic structure $(7.73 \%, \pm 0.25 \%$ of pairwise comparisons of fungal MLG; Table S3). Hence,

374 despite the predominance of vertical transmission, horizontal transmission plays a non-negligible 
375 role in shaping the genetic composition of the lichen population.

376 Our approach, however, does not allow to distinguish the effect of horizontal transmission of

377 the photobiont related to fungal sexual reproduction from the process of horizontal movement of

378 photobiont from nearby vegetative propagules, which may affect the interpretation of our results

379 through reshuffling of the genetic composition of lichen thalli independently from fungal sexual

380 reproduction. Previous studies have shown that, even where both partners are co-dispersed in

381 specialized propagules, de-differentiation (separation of algal and fungal partners) allows vertically

382 transmitted algae to be replaced by others available in the environment, or even to be captured from

383 other nearby lichen species (Friedl 1987; Ott et al. 1995; Ohmura et al. 2006; Wornik \& Grube

384 2010; Dal Grande 2011). The frequency of such algal substitutions in nature is unknown (Piercey-

385 Normore \& DePriest 2001), but this strategy may provide a mechanism for optimizing symbiotic

386 composition in a local environment (Friedl 1987; Ott 1987b; Ohmura et al. 2006; Yahr et al. 2006).

387 The way horizontal algal movement and relichenization take place remains elusive, and these

388 processes deserve further attention. They may well be key evolutionary processes in lichen

389 communities, allowing the formation of photobiont-mediated guilds among unrelated lichen-forming

390 fungi (Beck et al. 2002; Rikkinen et al. 2002; Rikkinen 2003). In other symbioses, evidence for

391 horizontal symbiont transmission has been reported, for instance in certain corals and their

392 symbiotic dinoflagellates (Rowan 1998; Loh et al. 2001), in insects and their endosymbiotic bacteria

393 (Huigens et al. 2000; Sirviö \& Pamilo 2010), or in fungus-gardening ants or termites and fungal

394 cultivars (Aanen et al. 2002; Mikheyev et al. 2007). Our results showed that the lichen symbiosis is

395 formed by a strictly asexual partner (alga) and by a fungal partner that conserved the sexual pathway

396 together with the formation of asexual diaspores co-dispersing both partners. Sexual propagules are 
considered important for long-distance dispersal of the mycobiont (Walser 2004; Seymour et al.

398 2005; Cassie \& Piercey-Normore 2008; Scheidegger \& Werth 2009) and increase the number of

399 genotypes in local populations, thus potentially enhancing adaptation (Maynard Smith 1986; Samadi

400 et al. 1999; Rice \& Chippindale 2001; Blaha et al. 2006; Foucaud et al. 2006).

401 The symbiotic relationship is obligatory for the fungal partner in L. pulmonaria to complete

402 its life-cycle (Ott 1987b; Ingold \& Hudson 1993; Honegger 2001). Yet, little is known about how

403 often and under what conditions sexual reproduction and relichenization occur in natural habitats. So

404 far, no corresponding estimates from molecular data were available (Honegger 2001; Dobson 2003).

405 Our study suggests that independent dispersal of the symbionts does occur in natural populations of

406 L. pulmonaria and that it has a considerable impact on the genetic diversity of lichen populations.

408 Spatial genetic structure

409 We analyzed the spatial genetic structure of lichen populations to infer about dispersal processes

410 related to horizontal and vertical transmission of the photobiont. While statistical analysis of spatial

411 patterns is often limited by the lack of replicate study areas, the availability of comparable spatial

412 genetic data from 62 replicate populations allowed robust statistical analysis based on bootstrap

413 estimates.

414 Here we showed that the fungal and algal clonal components had a large impact on the small-

415 scale spatial genetic structure of the lichen association, and the signal of clonality markedly

416 decreased within a distance of about $20 \mathrm{~m}$ (Fig. 4). Our results indicate that vegetative propagules

417 play a dominant role to disperse genetically identical symbionts of L. pulmonaria over short spatial

418 distances within populations. They are thus a means of rapid lichen spread at the local scale 
419 (Hawksworth \& Hill 1984; Heinken 1999; Dettki et al. 2000; Sillett et al. 2000). The restricted

420 dispersal can be explained by these propagules' larger size compared to fungal ascospores, since the

421 larger the propagule the shorter the distance they can be carried by wind, water or animals (Heinken

422 1999; Walser 2004; Werth et al. 2006b; Scheidegger \& Werth 2009).

423 The differences in the reproductive modes between the two symbionts of L. pulmonaria

424 described above were clearly reflected in their spatial genetic structure. We expected that the

425 symbionts mainly spread within the vegetative propagules of the lichen, and thus would present

426 similar spatial structures. The alga, which only showed a signal of mutation, confirmed this

427 assumption by displaying almost an identical spatial pattern as the clones (with deltaA=deltaF=0;

428 Fig. 5). The fungus, which showed signals of both mutation and recombination, exhibited a different 429 spatial genetic structure suggesting dispersal over larger distances.

431 Conclusions

432 This paper presents a novel approach to analyze relatively recent, within population micro-

433 evolutionary processes from the population genetic structure of the lichen L. pulmonaria. We 434 provided robust evidence for the predominance of vertical transmission of the photobiont at the 435 intra-population level in a mainly vegetative species.

436 As a caveat, we recall some key assumptions to our analysis. First, we assume that long437 distance migration leads to the introduction of new genotypes, i.e., that it is unlikely that the same 438 MLG would originate independently in two populations and migrate from one to the other, thus 439 reflecting larger-scale processes within our data set B. Based on observed allele frequencies within 440 populations, we estimated the probability of independent origin of clones as $<0.1 \%$ each for the 
441 fungus and the alga. The probability of independent origin in different populations and subsequent

442 immigration is expected to be much lower still. Second, we assume that each mutation leads to a

443 new allele, such as expected under an infinite-alleles mutation model. Multiple identical but

444 independent mutations within the same population, as might be expected under a step-wise mutation

445 model, would lead to underestimation of the relative contribution of mutation due to the exclusion of

446 recurrent MLGs in data set C. Third, we assumed independent mutation in both symbionts at the

447 same time to be negligible, and we estimated its probability as $<1 \%$ of the probability of mutation in

448 either symbiont. Concurrent mutation in both symbionts would reduce the relative size of data set B

449 but should not otherwise bias results.

450 We inferred the different processes shaping the genetic structure of the symbionts,

451 highlighting that, even in a species with rare sexual reproduction such as L. pulmonaria, fungal

452 recombination is a process shaping the genetic structure between the two lichen symbionts. The

453 possibility of sexual reproduction is important to population genetics. Considering the low

454 germination rate in some lichen species, it may seem unlikely that their ascospores would ever

455 develop into a lichen thallus. However, even if only a few out of the thousands of ascospores

456 produced in one ascoma find the proper photobiont to reconstitute the symbiosis, as long as the new

457 thallus multiplies and disperses through vegetative propagules, this may suffice to alter lichen

458 population genetic structure (Honegger \& Zippler 2007).

\section{Acknowledgments}

461 This research was founded by the Swiss National Science Foundation (projects 31003A-105830 and 462 31003A-127346 to C Scheidegger) and an NSERC Discovery Grant (to HH Wagner). We are 
463 grateful to James B. Anderson, Rolf Holderegger and four anonymous reviewers for valuable

464 suggestions on the manuscript, Ariel Bergamini for assistance with statistical analyses, Heather

465 Cole, Carolina Cornejo and Silke Werth for comments of the manuscript, Vladimir Mikryukov,

466 Christine Keller and other collaborators (listed in Table S1, Supporting Information) for field

467 collection of samples. Authors acknowledge the Genetic Diversity Center at ETH Zürich,

468 Switzerland (CCED-GDC) for technical assistance.

$470 \quad$ Literature cited

471 Aanen DK, Eggleton P, Rouland-Lefevre C, Guldberg-Froslev T, Rosendahl S, Boomsma JJ (2002)

472 The evolution of fungus-growing termites and their mutualistic fungal symbionts. Proceedings of 473 the National Academy of Sciences USA, 99, 14887-14892.

474 Ahmadjian V (1959) Experimental observations on the algal genus Trebouxia de Puymaly. Svensk $475 \quad$ Botanisk Tidskrift, 53, 71-80.

476 Ahmadjian V (1993) The lichen symbiosis. John Wiley, New York, USA.

477 Ally D, Ritland K, Otto SP (2008) Can clone size serve as a proxy for clone age? An exploration 478 using microsatellite divergence in Populus tremuloides. Molecular Ecology, 17, 4897-4911.

479 Andras JP, Kirk NL, Harvell CD (2011) Range-wide population genetic structure of Symbiodinium 480 associated with the Caribbean Sea fan coral, Gorgonia ventalina. Molecular Ecology, 20, $2525-$ 4812542.

482 Arnaud-Haond S, Belkhir K (2006) GENCLONE: a computer program to analyse genotypic data, 483 test for clonality and describe spatial clonal organization. Molecular Ecology Notes, 7, 15-17. 484 Arnaud-Haond S, Duarte CM, Alberto F, Serrao EA (2007) Standardazing methods to address 
485 clonality in population studies. Molecular Ecology, 16, 5115-5139.

486 Beck A, Friedl T, Rambold G (1998) Selectivity of photobiont choice in a defined lichen

487 community: inferences from cultural and molecular studies. New Phytologist, 139, 709-720.

488 Beck A, Kasalicky T, Rambold G (2002) Myco-photobiontal selection in a Mediterranean

489 cryptogam community with Fulgensia fulgida. New Phytologist, 153, 317-326.

490 Blaha J, Baloch E, Grube M (2006) High photobiont diversity associated with the euryoecious

491 lichen-forming ascomycete Lecanora rupicola (Lecanoraceae, Ascomycota). Biological Journal

492 of the Linnean Society, 88, 283-293.

493 Boch S, Prati D, Werth S, Rüetschi J, Fischer M (2011) Lichen endozoochory by snails. PloS ONE

$494 \quad 6(4)$, e18770. doi:10.1371/journal.pone.0018770.

495 Brem D, Leuchtmann A (2003) Molecular evidence for host-adapted races of the fungal endophyte

496 Epichloe bromicola after presumed host-shifts. Evolution, 57, 37-51.

497 Brown BE, Dunne RP, Goodson MS, Douglas AE (2000) Marine ecology: bleaching patterns in reef

$498 \quad$ corals. Nature, $\mathbf{4 0 4}, \mathbf{1 4 2 - 1 4 3 .}$

499 Bubrick P, Frensdorff A, Galun M (1985) Selectivity in the lichen symbiosis. In: Lichen Physiology

500 and Cell Biology (ed. Plenum), pp. 319-334. Brown, D.H., New York.

501 Butlin R (2002) The costs and benefits of sex: new insights from old asexual lineages. Nature, 3, $502 \quad 311-317$.

503 Cassie D, Piercey-Normore MD (2008) Dispersal in a sterile lichen-forming fungus, Thamnolia

504 subuliformis (Ascomycotina, Icmadophilaceae). Canadian Journal of Botany, 86, 751-762.

505 Clay K (1990) Fungal endophytes of grasses. Annual Review of Ecology and Systematics, 21, 275506297. 
507 Clay K (1988) Fungal endophytes of grasses: a defensive mutualism between plants and fungi.

508 Ecology, 69, 10-16.

509 Coates AG, Jackson JBC (1987) Clonal growth, algal symbiosis, and reef formation by corals.

$510 \quad$ Paleobiology, 13, 363-378.

511 Dal Grande F (2011) Phylogeny and co-phylogeography of a photobiont-mediated guild in the

512 lichen family Lobariaceae. PhD Thesis, University of Bern, Bern, Switzerland.

513 Dal Grande F, Widmer I, Beck A, Scheidegger C (2010) Microsatellite markers for Dictyochloropsis

514 reticulata (Trebouxiophyceae), the symbiotic alga of the lichen Lobaria pulmonaria (L.).

$515 \quad$ Conservation Genetics, 11, 1147-1149.

516 Dettki H, Klintberg P, Esseen PA (2000) Are epiphytic lichens in young forests limited by local

517 dispersal? Ecoscience, 7, 317-325.

518 Dobson F (2003) Getting a liking for lichens. Biologist, 50, 263-267.

519 Doering M, Piercey-Normore MD (2009) Genetically divergent algae shape an epiphytic lichen

520 community on Jack Pine in Manitoba. Lichenologist, 41, 69-80.

521 Etges S, Ott S (2001) Lichen mycobionts transplanted into the natural habitat. Symbiosis, 30, 191522206.

523 Foucaud J, Jourdan H, Le Breton J, Loiseau A, Konghouleux D, Estoup A (2006) Rare sexual

524 reproduction events in the clonal reproduction system of introduced populations of the little fire 525 ant. Evolution, 60, 1646-1657.

526 Friedl T (1987) Thallus development and phycobionts of the parasitic lichen Diploschistes 527 muscorum. Lichenologist, 19, 183-191.

528 Friedl T, Büdel B (2008) Photobionts. In: Lichen Biology. 2nd ed. (ed. Nash TH III), pp. 9-26. 
529 Cambridge University Press, Cambridge UK.

530 Gaßmann A, Ott S (2000) Growth strategy and the gradual symbiotic interactions of the lichen

531 Ochrolechia frigida. Plant Biology, 2, 368-378.

532 Geller JB, Walton ED (2001) Breaking up and getting together: evolution of symbiosis and cloning

533 by fission in sea anemones (genus Anthopleura). Evolution, 55, 1781-1794.

534 Gilbert OM, Queller DC, Strassmann JE (2009) Discovery of a large clonal patch of a social

535 amoeba: implications for social evolution. Molecular Ecology, 18, 1273-1281.

536 Handa S, Ohmura Y, Nakano T, Nakahara-Tsubota M (2007) Airborne green microalgae

537 (Chlorophyta) in snowfall. Hikobia, 15, 109-120. (in Japanese)

538 Hawksworth DL, Hill DJ (1984) The lichen-forming fungi. pp. Glasgow \& London: Blackie.

539 Hedenås H, Blomberg P, Ericson L (2007) Significance of old aspen (Populus tremula) trees for the

$540 \quad$ occurrence of lichen photobionts. Biological Conservation, 135, 380-387.

541 Heinken T (1999) Dispersal patterns of terricolous lichens by thallus fragments. Lichenologist, 31, $542 \quad 603-612$.

543 Higgs $\mathrm{P}$, Woodcock $\mathrm{G}$ (1995) The accumulation of mutations in asexual populations and the

544 structure of genealogical trees in the presence of selection. Journal of Mathematical Biology, 33, $545 \quad 677-702$.

546 Hill DJ (2009) Asymmetric co-evolution in the lichen symbiosis caused by a limited capacity for 547 adaptation in the photobiont. Botanical Review, 75, 326-338.

548 Honegger R (1998) The lichen symbiosis-what is so spectacular about it? Lichenologist, 30, 193549212.

550 Honegger R (2001) The symbiotic phenotype of lichen-forming ascomycetes. In: The Mycota IX, 
$551 \quad$ Fungal Associations (ed. Hock B), pp. 165-188. Springer, Berlin.

552 Honegger R (2008) Morphogenesis. In: Lichen Biology. 2nd ed. (ed. Nash TH III), pp. 69-93.

553 Cambridge University Press, Cambridge UK.

554 Honegger R, Zippler U (2007) Mating systems in representatives of Parmeliaceae, Ramalinaceae 555 and Physiaceae (Lecanoromycetes, lichen-forming ascomycetes). Mycological Research, 111, $556 \quad 424-432$.

557 Huigens ME, Luck RF, Klaassen RH, Masas MF, Timmermans MJ, Stouthamer R (2000) Infectious 558 parthenogenesis. Nature, 405, 178-179.

559 Ingold CT, Hudson HJ (1993) The Biology of Fungi. 6th ed. 224 pp. Chapman and Hall, London.

560 Lättman H, Lindblom L, Mattsson J-E, Milberg P, Skage M, Ekman S (2009) Estimating the

561 dispersal capacity of the rare lichen Cliostomum corrugatum. Biological Conservation, 142, $562 \quad 1870-1878$.

563 Lindblom L, Ekman S (2005) Molecular evidence supports the distinction between Xanthoria

564 parietina and X. aureola (Teloschistaceae, lichenized Ascomycota). Mycological Research, 109, $565 \quad$ 187-199.

566 Lindblom L, Ekman S (2007) New evidence corroborates population differentiation in Xanthoria 567 parietina. Lichenologist, 39, 259-271.

568 Loh WKW, Loi T, Carter D, Hoegh-Guldberg O (2001) Genetic variability of the symbiotic

569 dinoflagellates from the wide ranging coral species Seriatopora hystrix and Acropora

$570 \quad$ longicyathus in the Indo-West Pacific. Marine Ecology Progress Series, 222, 97-107.

571 Lohtander K, Oksanen I, Rikkinen J (2003) Genetic diversity of green algal and cyanobacterial 572 photobionts in Nephroma (Peltigerales). Lichenologist, 35, 325-339. 
573 Lücking R, Grube M (2002) Facultative parasitism and reproductive strategies in Chroodiscus

574 (Ascomycota, Ostropales). Stapfia, 80, 267-292.

575 Macedo MF, Miller AZ, Dionisio A, Saiz-Jimenez C (2009) Biodiversity of cyanobacteria and green 576 algae on monuments in the Mediterranean basin. Microbiology, 155, 3476-3490.

577 Margulis L (1993) Symbiosis in cell evolution: microbial communities in the Archean and 578 Proterozoic eons. 2nd ed. 452 pp. Freeman WH and Co, New York.

579 Maynard Smith J (1986) Evolution: contemplating life without sex. Nature, 324, 300-301.

580 Meier FA, Scherrer S, Honegger R (2002) Faecal pellets of lichenivorous mites contain viable cells 581 of the lichen-forming ascomycete Xanthoria parietina and its green algal photobiont, Trebouxia 582 arboricola. Biological Journal of the Linnean Society, 76, 259-268.

583 Mikheyev AS, Mueller UG, Boomsma JJ (2007) Population genetic signatures of diffuse co584 evolution between leaf-cutting ants and their cultivar fungi. Molecular Ecology, 16, 209-216. 585 Mock KE, Rowe CA, Hooten MB, Dewoody J, Hipkins VD (2008) Clonal dynamics in western 586 North American aspen ( Populus tremuloides ). Molecular Ecology, 17, 4827-4844.

587 Moran N, Baumann P (1994) Phylogenetics of cytoplasmically inherited microorganisms of 588 arthropods. Trends in Ecology and Evolution, 9, 15-20.

589 Mukhtar A, Garty J, Galun M (1994) Does the lichen alga Trebouxia occur free-living in nature: $590 \quad$ further immunological evidence. Symbiosis, 17, 247- 253.

591 Nash TH III (1996) Nitrogen, its metabolism and potential contribution to ecosystems. In: Nash TH 592 III (ed) Lichen biology, pp 121-135. Cambridge University Press, Cambridge UK.

593 Nelsen MP, Gargas A (2008) Dissociation and horizontal transmission of codispersing lichen 594 symbionts in the genus Lepraria (Lecanorales: Stereocaulaceae). New Phytologist, 177, $264-275$. 
595 Nelsen MP, Gargas A (2009) Symbiont flexibility in Thamnolia vermicularis (Pertusariales:

596 Icmadophilaceae). Bryologist, 112, 404-417.

597 Ohmura Y, Kawachi M, Kasai F, Watanabe MM, Takeshita S (2006) Genetic combinations of 598 symbionts in a vegetatively reproducing lichen, Parmotrema tinctorum, based on ITS rDNA 599 sequences. Bryologist, 109, 43-59.

600 Ott S (1987a) Sexual reproduction and developmental adaptations in Xanthoria parietina. Nordic 601 Journal of Botany, 7, 219-228.

602 Ott S (1987b) Reproductive strategies in lichens. Bibliotheca Lichenologica, 25, 81-93.

603 Ott S, Meier T, Jahns HM (1995) Development, regeneration, and parasitic interactions between the 604 lichens Fulgensia bracteata and Toninia caeruleonigricans. Canadian Journal of Botany, 73, $605 \quad$ S595-S602.

606 Parks JC, Werth CR (1993) A study of spatial features of clones in a population of bracken fern 607 Pteridium aquilinum (L) Kuhn. American Journal of Botany, 80, 537-544.

608 Paulsrud P, Rikkinen J, Lindblad P (1998) Cyanobiont specificity in some Nostoc-containing lichens 609 and in a Peltigera aphthosa photosymbiodeme. New Phytologist, 139, 517-524.

610 Piercey-Normore MD (2006) The lichen-forming ascomycete Evernia mesomorpha associates with 611 multiple genotypes of Trebouxia jamesii. New Phytologist, 169, 331-344.

612 Piercey-Normore MD and DePriest PT (2001) Algal switching among lichen symbioses. American 613 Journal of Botany, 88, 1490-1498.

614 Printzen C, Ekman S (2003) Local population subdivision in the lichen Cladonia subcervicornis as 615 revealed by mitochondrial cytochrome oxidase subunit 1 intron sequences. Mycologia, 95, 399616406. 
617 Printzen C, Ekman S, Tønsberg T (2003) Phylogeography of Cavernularia hultenii: Evidence of 618 slow genetic drift in a widely disjunct lichen. Molecular Ecology, 12, 1473-1486.

619 R Development Core Team (2008) R: A language and environment for statistical computing. R 620 Foundation for statistical computing, Vienna, Austria. http://www.R-project.org .

621 Rambold G, Triebel D (1992) The inter-Lecanoralean associations. Bibliotheca Lichenologica, 48, $622 \quad 1-201$.

623 Reeve HK, Hölldobler B (2007) The emergence of a superorganism through intergroup competition.

624 Proceedings of the National Academy of Sciences USA, 104, 9736-9740.

625 Rice WR, Chippindale AK (2001) Sexual recombination and the power of natural selection. Science, 626 294, 555-559.

627 Richardson DHS (1999) War in the world of lichens: parasitism and symbiosis as exemplified by 628 lichens and lichenicolous fungi. Mycological Research, 103, 641-650.

629 Rikkinen J (2003) Ecological and evolutionary role of photobiont-mediated guilds in lichens. 630 Symbiosis, 34, 99-110.

631 Rikkinen J, Oksanen I, Lohtander K (2002) Lichen guilds share related cyanobacterial symbionts. $632 \quad$ Science, 297, 357-357.

633 Rowan R (1998) Diversity and ecology of Zooxanthellae on coral reefs. Journal of Phycology, 34, $634 \quad 407-417$.

635 Saffo MB (1992) Invertebrates in endosymbiotic associations. Annals of Zoology, 32, 557-565.

636 Saikkonen K, Ion D, Gyllenberg M (2002) The persistence of vertically transmitted fungi in grass 637 metapopulations. Proceedings of the Royal Society of London, Series B, 269, 1397-1403.

638 Samadi S, Mavarez J, Pointier JP, Delay B, Jarne P (1999) Microsatellite and morphological 
639 analysis of population structure in the parthenogenetic freshwater snail Melanoides tuberculata: 640 insights into the creation of clonal variability. Molecular Ecology, 8, 1141-1153.

641 Sanders WB (2005) Observing microscopic phases of lichen life cycles on transparent substrata 642 placed in situ. Lichenologist, 37, 373-382.

643 Sanders WB, Lücking R (2002) Reproductive strategies, relichenization and thallus development 644 observed in situ in leaf-dwelling lichen communities. New Phytologist, 155, 425-435.

645 Scheidegger C (1985) Systematische Studien zur Krustenflechte Anzina carneonivea (Trapeliaceae, 646 Lecanorales). Nova Hedwigia 41, 191-218.

647 Scheidegger C, Werth S (2009) Conservation strategies for lichens: insights from population 648 biology. Fungal Biology Reviews, 23, 55-66.

649 Seabloom EW, Bjørnstad ON, Bolker BM, Reichman OJ (2005) The spatial signature of 650 environmental heterogeneity, dispersal, and competition in successional grasslands. $651 \quad$ Ecological Monographs, 75, 199-214.

652 Selkoe KA, Toonen RJ (2006) Microsatellites for ecologists: a pratictical guide to using and 653 evaluating microsatellite markers. Ecology Letters, 9, 615-629.

654 Seymour FA, Crittenden PD, Dyer PS (2005) Sex in the extremes: lichen-forming fungi. Mycologist, $655 \quad 19,51-58$

656 Sillett SC, McCune B, Peck JE, Rambo TR, Ruchty A (2000) Dispersal limitations of epiphytic 657 lichens result in species dependent on old-growth forests. Ecological Applications, 10, 789-799.

658 Sirviö A, Pamilo P (2010) Multiple endosymbionts in populations of the ant Formica cinerea. BMC 659 Evolutionary Biology, 10, 335.

660 Skaloud P (2008) Polyphasic approaches in the taxonomy of green aerophytic algae. PhD Thesis, 
661 University of Prague. Prague, Czech Republic.

662 Slocum RD, Ahmadjian V, Hildreth KC (1980) Zoosporogenesis in Trebouxia gelatinosa:

663 ultrastructure potential for zoospore release and implications for the lichen association.

664 Lichenologist, 12, 173-187.

665 Sluiman HJ, Kouwets FAC, Blommers PCJ (1989) Classification and definition of cytokinetic

666 patterns in green algae: sporulation versus (vegetative) cell division. Arch. Protistenk, 137, 277-

66790.

668 Stenroos S (1990) Cladonia luteoalba - an enigmatic Cladonia. Karstenia, 30, 27-32.

669 Tschermak-Woess E (1978) Über die Phycobionten der Sektion Cystophora von Chaenotheca, 670 insbesondere Dictyochloropsis splendida und Trebouxia simplex, spec. nova. Plant Systematics 671 and Evolution, 129, 185-208.

672 Tomiuk J, Guldbrandtsen B, Loeschcke V (1998) Population differentiation through mutation and 673 drift - a comparison of genetic identity markers. Genetica, 102/103, 545-558.

674 Vogler AJ, Keys C, Nemoto Y, Colman RE, Jay Z, Keim P (2006) Effect of repeat copy number on 675 variable-number tandem repeat mutations in Escherichia coli O157:H7. Journal of Bacteriology, $676 \quad \mathbf{1 8 8}, 4253-4263$.

677 Wagner HH, Fortin MJ (2005) Spatial analysis of landscapes: concepts and statistics. Ecology 86, $678 \quad 1975-1987$.

679 Wagner HH, Holderegger R, Werth S, Gugerli F, Hoebee SE, Scheidegger C (2005) Variogram 680 analysis of the spatial genetic structure of continuous populations using multilocus microsatellite 681 data. Genetics, 169, 1739-1752.

682 Wagner HH, Werth S, Kalwij JM, Bolli JC, Scheidegger C (2006) Modelling forest recolonization 
683 by an epiphytic lichen using a landscape genetic approach. Landscape Ecology, 21, 849-865.

684 Walser JC, Sperisen C, Soliva M, Scheidegger C (2003) Fungus-specific microsatellite primers of 685 lichens: application for the assessment of genetic variation on different spatial scales in Lobaria 686 pulmonaria. Fungal Genetics and Biology, 40, 72-82.

687 Walser, JC (2004) Molecular evidence for limited dispersal of vegetative propagules in the epiphytic 688 lichen Lobaria pulmonaria. American Journal of Botany, 91, 1273-1276.

689 Werth S (2010) Optimal sample sizes and allelic diversity in studies of the genetic variability of 690 mycobiont and photobiont populations. Lichenologist, 43, 73-81.

691 Werth S, Gugerli F, Holderegger R, Wagner HH, Csencsics D, Scheidegger C (2007) Landscape-

692 level gene flow in Lobaria pulmonaria, an epiphytic lichen. Molecular Ecology, 16, 2807-2815.

693 Werth S, Sork VL (2010) Identity and genetic structure of the photobiont of the epiphytic lichen 694 Ramalina menziesii on three oak species in southern California. American Journal of Botany, 97, $695 \quad 821-830$.

696 Werth S, Wagner HH, Gugerli F, Holderegger R, Csencsics D, Kalwij JM, Scheidegger C. (2006)a.

697 Quantifying dispersal and establishment limitation in a population of an epiphytic lichen.

$698 \quad$ Ecology, 87, 2037-2046.

699 Werth S, Wagner HH, Holderegger R, Kalwij JM, Scheidegger C. (2006)b. Effect of disturbances on 700 the genetic diversity of an old-forest associated lichen. Molecular Ecology, 15, 911-921.

701 Widmer I, Dal Grande F, Cornejo C, Scheidegger C (2010) Highly variable microsatellite markers 702 for the fungal and algal symbionts of the lichen Lobaria pulmonaria and challenges in developing 703 biont-specific molecular markers for fungal associations. Fungal Biology 114, 538-544.

704 Wornik S, Grube M (2010) Joint dispersal does not imply maintenance of partnerships in lichen 
symbioses. Microbial Ecology, 59, 150-157.

706 Yahr R, Vilgalys R, DePriest PT (2004) Strong fungal specificity and selectivity for algal symbionts

707 in Florida scrub Cladonia lichens. Molecular Ecology, 13, 3367-3378.

708 Yahr R, Vilgalys R, DePriest PT (2006) Geographic variation in algal partners of Cladonia

709 subtenuis (Cladoniaceae) highlights the dynamic nature of a lichen symbiosis. New Phytologist,

$710 \quad \mathbf{1 7 2}, 377-391$.

711 Yoshimura, I (1971) The genus Lobaria of Eastern Asia. Journal of the Hattori Botanical

$712 \quad$ Laboratory, 34, 231-331.

713 Zilber-Rosenberg I, Rosenberg E (2008) Role of microorganisms in the evolution of animals and

714 plants: the hologenome theory of evolution. FEMS Microbiology Reviews, 32, 723-735.

715 Zoller S, Lutzoni F, Scheidegger C (1999) Genetic variation within and among populations of the

716 threatened lichen Lobaria pulmonaria in Switzerland and implications for its conservation.

717 Molecular Ecology, 8, 2049-2059.

718

\section{Figure legends}

720 Fig. 1 Graphic representation of the pairwise analysis used in this study to infer the mode of

721 photobiont transmission and to analyze within-population micro-evolutionary processes of the

722 fungal and algal symbionts of L. pulmonaria. Each circle represents a single thallus of $L$.

723 pulmonaria. Each slice of the circle represents a microsatellite locus (eight for the fungal symbiont,

724 seven for the algal symbiont). Black (for fungal loci) or dark grey (for algal loci) slices represent

725 differences at the given microsatellite locus between Lichen A and Lichen B (top) or C (bottom).

726 The number of loci differing between a pair of thalli is defined for each symbiont as deltaA (alga) or 
deltaF (fungus).

729 Fig. 2 Models used to analyze the contribution of mutation and recombination to within-population

730 genetic structure of lichen symbionts in L. pulmonaria. Each barplot shows the relative frequency of

731 pairs of thalli differing in $\operatorname{deltaA}$ (alga, left) or deltaF (fungus, right) loci, as expected for each

732 symbiont under the empirical null model of recombination (top) or an exponential model of somatic

733 mutation (center). The bottom barplots show the observed relative frequency of pairs in data set C.

734 Empty circles indicate for each level of deltaA or deltaF the relative frequency predicted by the

735 fitted model combining the empirical null model of recombination and the exponential model of

736 mutation.

738 Fig. 3 Barplot of the relative frequency ( \pm bootstrap standard errors) of pairs of thalli (within 739 populations pooled over all populations) differing by 0-7 loci for the alga (deltaA) and 0-8 loci for

740 the fungus (deltaF) for all pairwise comparisons within each population and pooled over all

741 populations (data set A, top) and for pairwise comparisons in one symbiont constrained to identical

742 pairs of multilocus genotypes for the other symbiont (data set B, bottom).

744 Fig. 4 Spatial distribution of the following categories of thalli: vegetative propagules

745 (deltaF=deltaA=0; black bars, "00"), fungal clones associated with different algal multilocus

746 genotypes (deltaF $=0$ and deltaA $>0$; white bars, "01"), algal clones associated with different fungal

747 multilocus genotypes (deltaF $>0$ and deltaA=0; dark grey, "10"), and different fungal multilocus

748 genotypes associated with different algal multilocus genotypes (deltaF $>0$ and deltaA $>0$; light grey, 
749 "11"). The first distance class contained pairs of thalli sampled from the same tree. The last distance 750 class contained all sample comparisons at distances $>500 \mathrm{~m}$.

751

752 Fig. 5 Relative frequency of distance classes for each group of multilocus genotype pairs defined in

753 Fig. 2. Distance classes: 0-10m (first bar from bottom; darkest bars); 10-20m (second bar from

754 bottom); 20-50m (third bar from bottom); 50-100m (fourth bar from bottom); 100-200m (fifth bar

755 from bottom), $>500 \mathrm{~m}$ (last bar from bottom; faintest bars). The first distance class of pairs of thalli

756 sampled from the same tree was not included in the analysis. The total number of multilocus

757 genotype pairs per group is given on top of the corresponding bar.

758

759 Supporting Information

760 Table S1 Information on sampled populations of Lobaria pulmonaria.

761 Table S2 Microsatellite analysis: (a) primer sequences (Walser et al. 2003, 2004; this study; Dal

762 Grande et al. 2010), labeling, primer concentrations and (b, c) PCR conditions for genetic analyses

763 of Lobaria pulmonaria.

764 Table S3 Model fitting and residuals of observed frequencies of deltaF vs. fitted frequencies

765 (combined exponential and binomial fitting).

766 Table S4 Allele frequency distribution at eight fungal (LPu03, LPu09, LPu15, LPu23, LPu24,

767 LPu25, LPu28, Walser et al. 2003; Widmer et al. 2010; MS4, this study) and seven algal (LPh1 to

768 LPh7; Dal Grande et al. 2010) loci per population. Each line is one repeat length (allele) and each

769 number represents the absolute frequency of that allele in the particular population. 


\section{Author Information Box}

772 This work was part of Francesco Dal Grande and Ivo Widmer's PhD research on the evolutionary

773 history and co-phylogeography of a lichen symbiosis. Helene H. Wagner focuses on spatial analysis

774 and modelling of dispersal and inter-specific interactions applied in meta-community dynamics and

775 landscape genetics. Christoph Scheidegger's research interests cover the biodiversity evaluation,

776 population genetics and conservation biology of lichens and plants. 
Table 1 Data sets used in this study.

\begin{tabular}{c|l|l|l} 
Data set & Definition & Number of Pairs & Analysis \\
\hline $\mathbf{A}$ & $\begin{array}{l}\text { All pairs from within the } \\
\text { same population (same } \\
\text { for both symbionts) }\end{array}$ & $\begin{array}{l}\text { All: 36,218 pairs } \\
\text { from 62 populations }\end{array}$ & $\begin{array}{l}\text { Quantification of intra-population genetic diversity and spatial } \\
\text { genetic structure. }\end{array}$ \\
$\begin{array}{l}\text { Fungus: all pairs of } \\
\text { data set A with deltaA }=0 \\
\text { Alga: all pairs of } \\
\text { data set A with deltaF=0 } \\
\text { Data set B without } \\
\text { recurrent MLGs within } \\
\text { the same population }\end{array}$ & $\begin{array}{l}\text { Fungus: 2977 pairs } \\
\text { from 62 populations } \\
\text { Alga: 3285 pairs } \\
\text { from 62 populations } \\
\text { Fungus: } 269 \text { pairs } \\
\text { from 38 populations } \\
\text { other symbiont to partial out larger-scale evolutionary processes } \\
\text { when assessing the relative contribution of vertical transmission to } \\
\text { population genetic structure. }\end{array}$ & $\begin{array}{l}\text { Alga: 215 pairs } \\
\text { Exclusion of recurrent MLGs within populations to identify signals } \\
\text { of within-population mutation and recombination and to assess the } \\
\text { relative contribution of horizontal transmission. } \\
\text { This avoids potential underestimation of horizontal transmission in } \\
\text { genetically uniform or depauperate populations. }\end{array}$
\end{tabular}




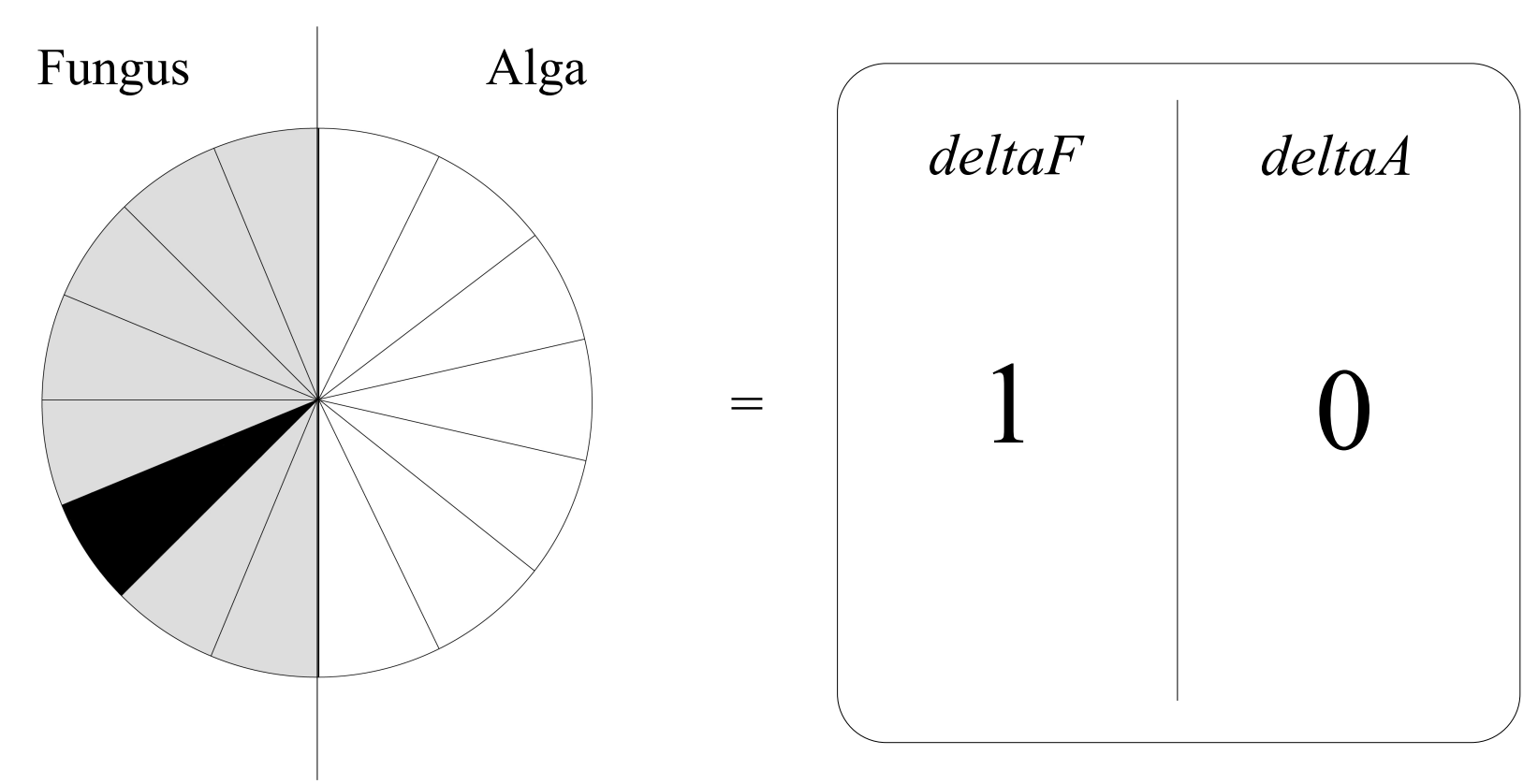

\section{LICHEN B}

LICHEN A
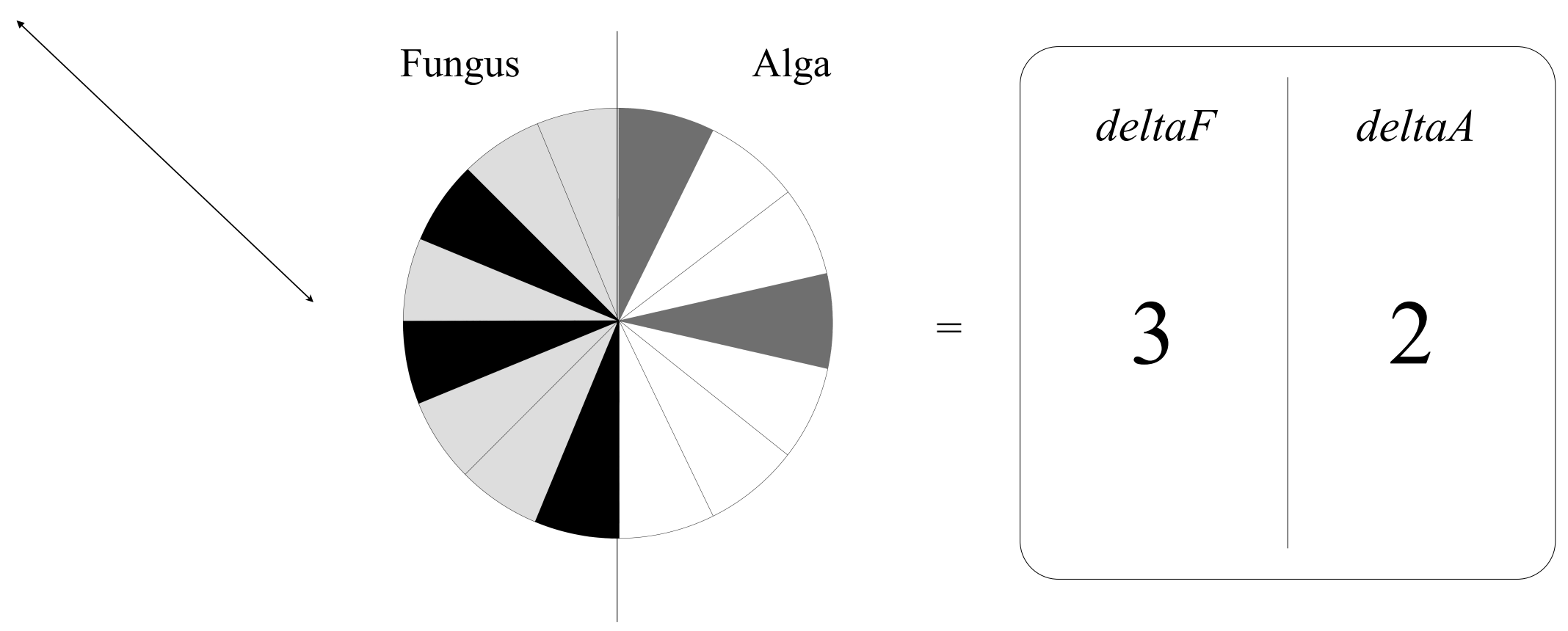

\section{LICHEN C}




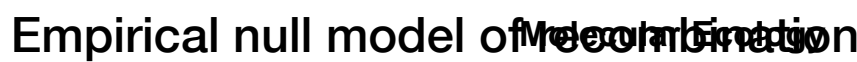

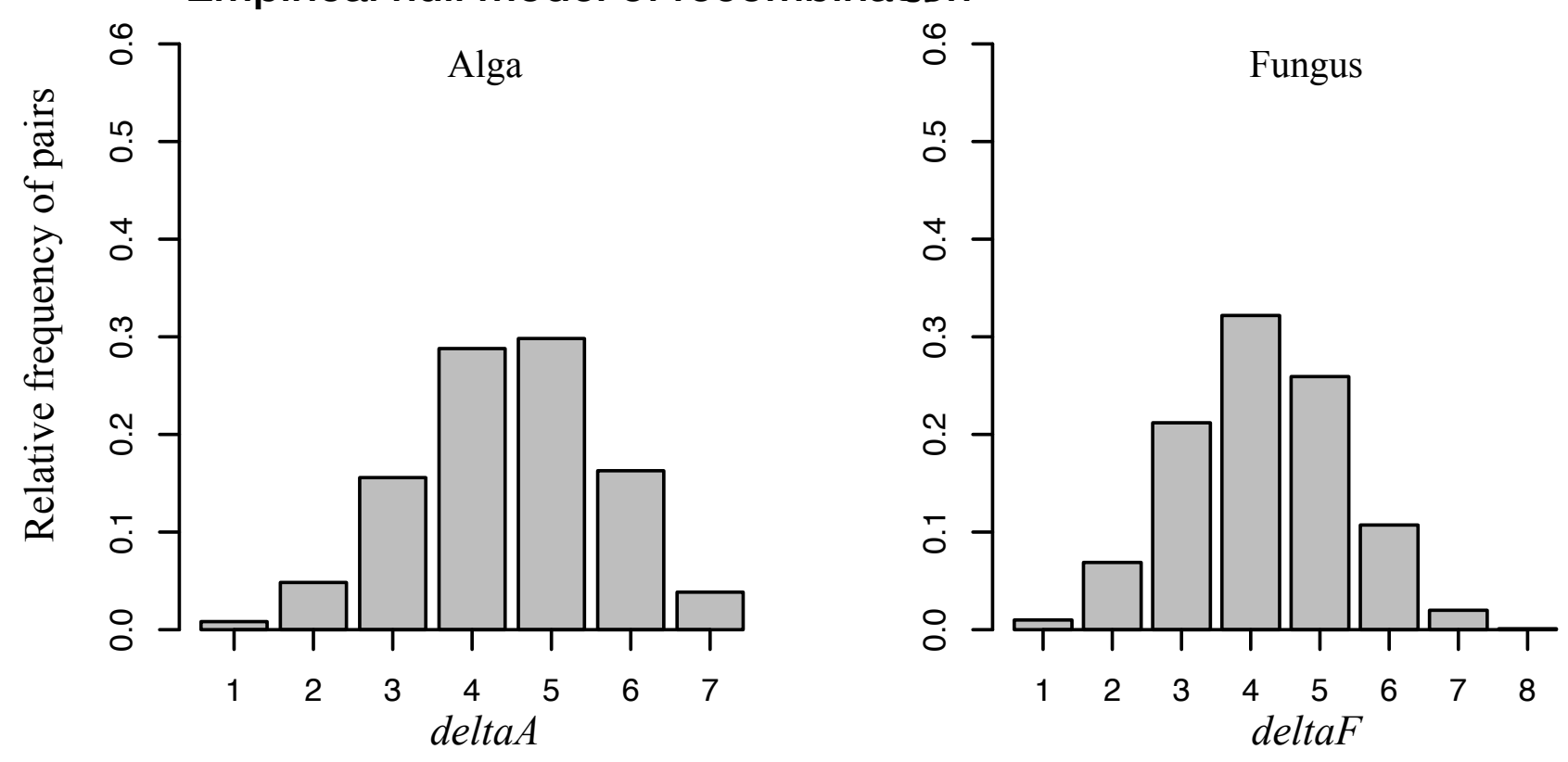

Exponential model of somatic mutation
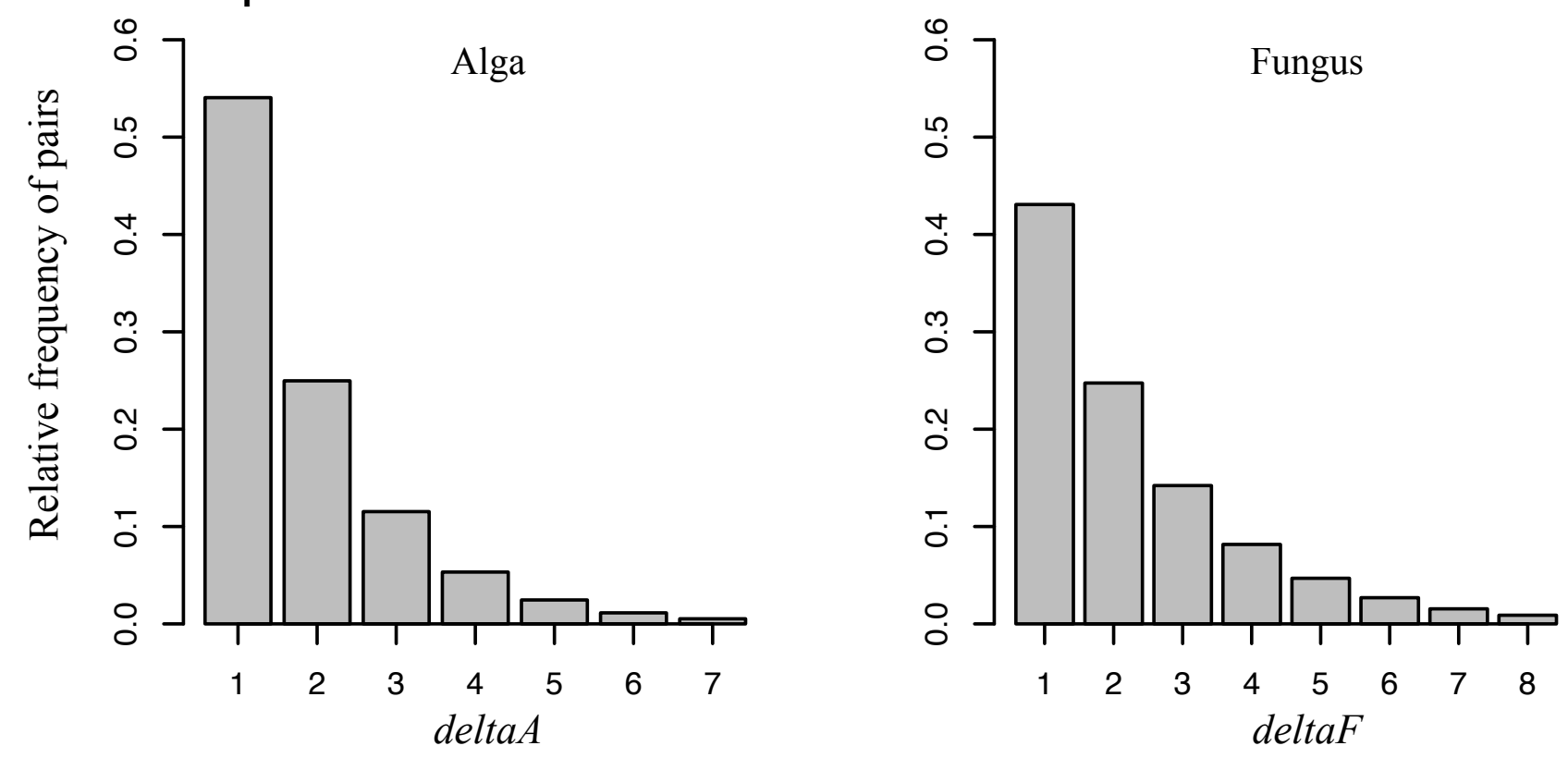

Observed distribution (data set $\mathrm{C}$ ) and fitted combined model
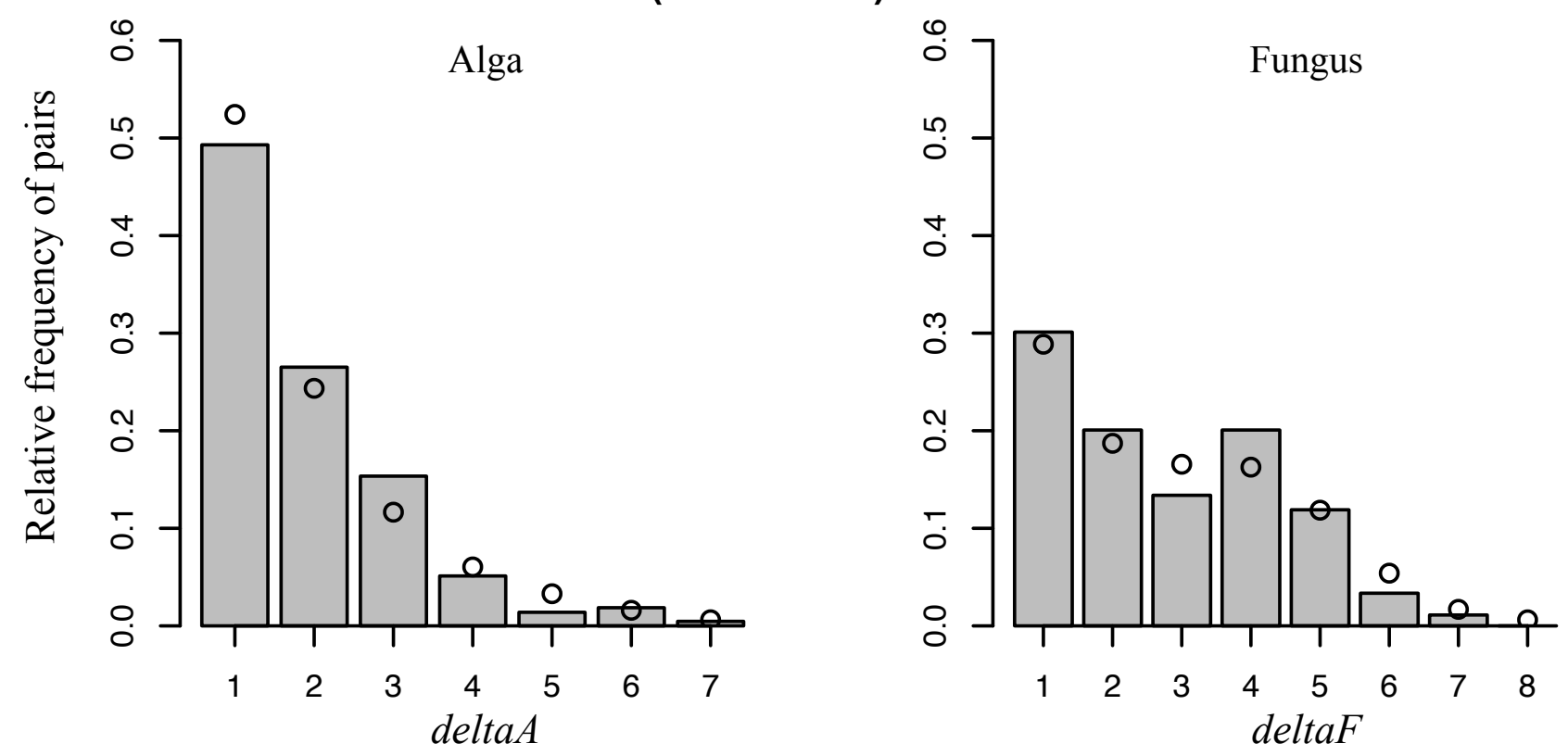


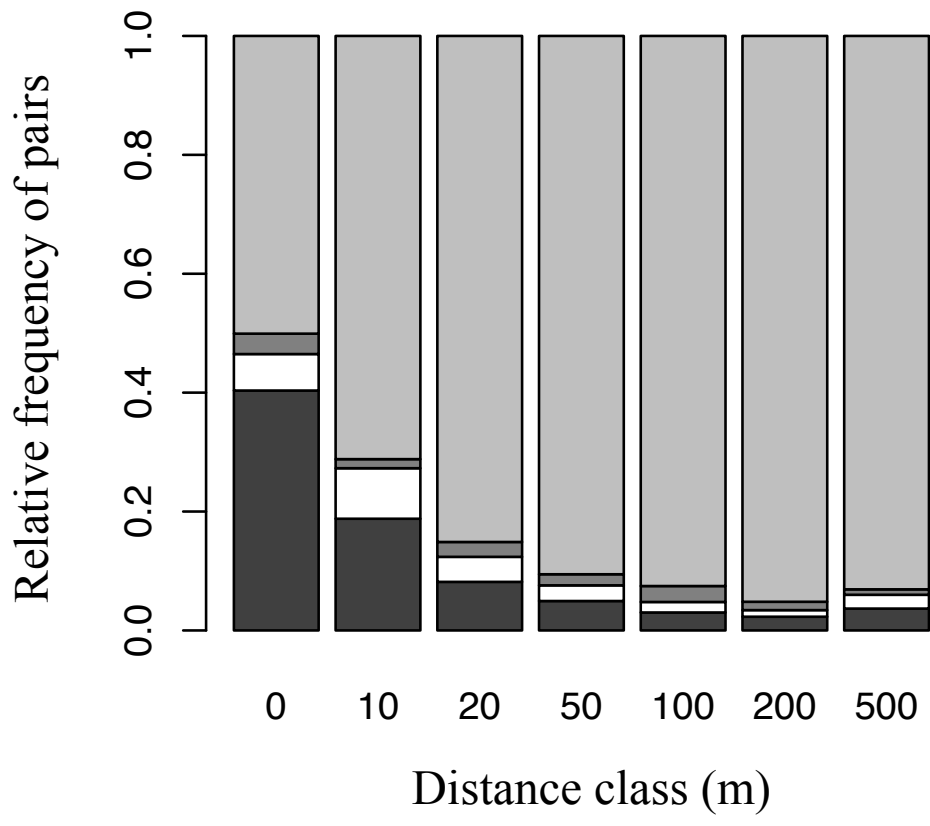




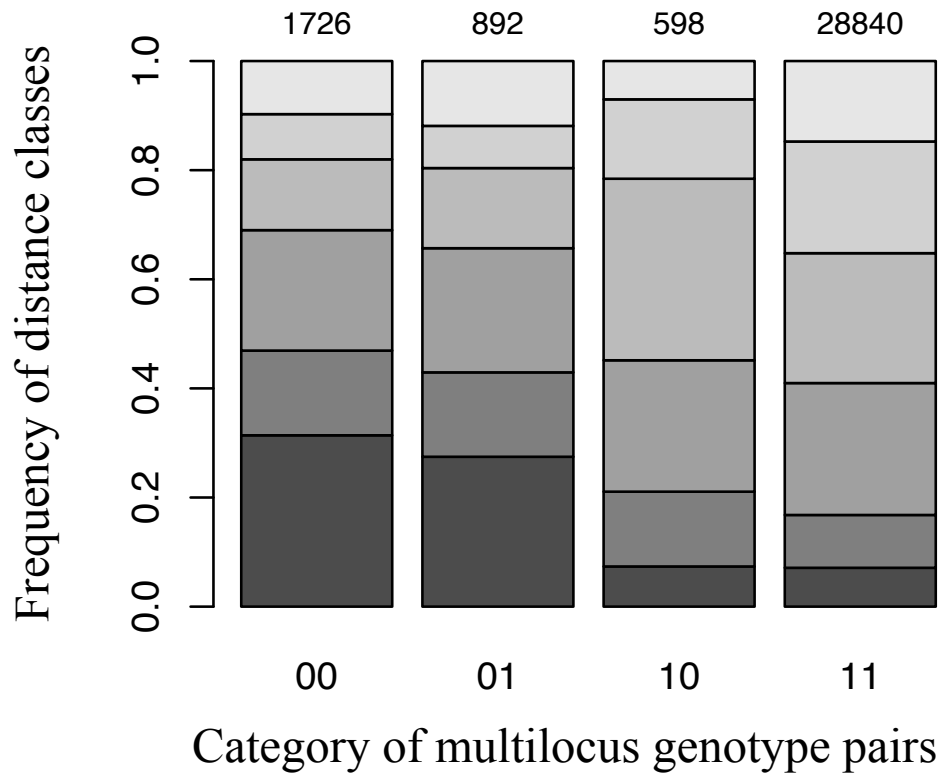

